${ }^{1}$ Faculty of Dentistry, Universitas Gadjah Mada, Indonesia.
Corresponding author:

Ryna Dwi Yanuaryska

Email: ryanuaryska@ugm.ac.id

Received: September 15, 2020

Accepted: January 21, 2021

\section{Alteration of mucosa cell maturation pattern after exposure to different radiographic imaging methods}

Ryna Dwi Yanuaryska ${ }^{1, *}$ (D) , Sabrina Ceasy Anggraeni ${ }^{1}$, Adhara Harvita Puspitasari', Rurie Ratna Shantiningsih ${ }^{1}$ (D) , Munakhir Mudjosemedi ${ }^{1}$ (D) , Rellyca Sola Gracea ${ }^{1}$ (D)

Aim: Dental imaging has been widely used for diagnosis in dentistry. However, dental X-ray may induce cytotoxicity leading to apoptosis in oral mucosa cells. The present study aimed to observe the maturation pattern of buccal and gingival cells after exposure to $X$-ray radiation from analog/digital panoramic scanning and cone beam computed tomography (CBCT). Methods: The research samples were 40 subjects who fulfilled the inclusion and exclusion criteria. The subjects were divided into the exposed (patients who received analog/digital panoramic radiography or CBCT) and controlled (patients who had no radiography examinations) groups, with 10 subjects in each group. Exfoliative cytology smears were obtained from buccal mucosa and gingiva before exposure (or on day 0 for the control group) and 10 days later. The cells were stained with the Papanicolaou method. Then, the superficial, intermediate, and parabasal cells were counted in each glass slide. Results: No significant differences $(p>0.05)$ were observed among all cell types between day 0 and 10 in the control group. Meanwhile, after exposure to three kinds of radiography examinations, the frequency of intermediate cells in buccal mucosa and gingiva increased $(p<0.05)$, but that of superficial cells decreased $(p<0.05)$ significantly. No significant difference was found in the parabasal cells $(p>0.05)$. The frequency differences between intermediate and superficial cells showed no significant difference between the buccal mucosa and gingiva. Conclusion: Analog/digital panoramic radiography and CBCT exposure can induce cytotoxicity by altering the maturation pattern of buccal mucosa cells and gingiva, so it is strongly recommended to only perform these procedures if necessary and avoid repeated exposure to the same patient.

Keywords: Papanicolaou test. Mouth mucosa. Cone-beam computed tomography. Gingiva. Radiography, panoramic. 


\section{Introduction}

The use of ionizing radiation in imaging science in dentistry has been rapidly increasing. The essential diagnostic method in dental practice is radiography, but X-ray provokes genotoxic and cytotoxic outcomes in cells. The genotoxic effects of $X$-rays are still debatable, whereas its cytotoxic effects are more proven. X-ray exposure through panoramic scanning initiates a cytotoxic consequence by increasing cell apoptosis ${ }^{1,2}$. The patients exposed to a series of radiographs had a significant increase in cellular death marked by pyknosis, karyolysis, and karyorrhexis in buccal mucosa smears. Cone beam computed tomography (CBCT) is a widely used oral-maxillofacial imaging modality which provides accurate 3D imaging of hard tissue structure ${ }^{3}$. Radiation exposure from CBCT also acts as a cytotoxicant to oral mucosa cells due to its high radiation dose. The patients submitted to CBCT show higher cell death than conventional radiographs group ${ }^{4}$. Cytotoxicants act by disrupting the molecules involved in cell growth and cell death ${ }^{5}$.

The oral epithelium has been widely used to analyze X-ray effects because it is directly exposed to radiation, and the tissue is easily collected by scraping the mucosa. The effects of X-ray exposure can be studied using exfoliative cytology because the method is simple, low-cost, and non-invasive ${ }^{6}$. Papanicolaou staining is a cytology method that analyzes the proportion of exfoliated cells as the maturation pattern. Thus, this method was applied in this study. The oral epithelium is continuously renewed; new cells migrate from the parabasal layer to the outer tissue layer, causing epithelial maturation?. Normally, oral mucosa smears consist of cells from the superficial, intermediate, and rare cases, the parabasal layer. Normal maturation pattern indicates the predominance of intermediate cells accompanied by superficial cells and rarely parabasal cells. Lesions in oral mucosal cells such as leucoplakia and oral squamous cell carcinoma have been associated with the maturation pattern changes indicated by a greater number of intermediate or parabasal cells ${ }^{8}$.

Studies have evaluated the influence of extrinsic factors, such as tobacco and alcohol consumption, on the process of oral epithelium maturation, given that they have been suggested as risk factors for oral cancer development ${ }^{8-10}$. Dental X-rays stimulate cytotoxic consequences in oral mucosa cells, leading to cellular death, and may be considered as a nongenotoxic mechanism of carcinogenesis ${ }^{1,2}$. However, whether $X$-ray radiation exposure affects epithelial maturation's normal process in the oral cavity remains uncertain. Thus, this study aimed to evaluate the outcomes of X-ray exposure from analog/digital panoramic radiography and CBCT on the maturation patterns of buccal and gingival cells.

\section{MATERIAL AND METHODS}

\section{Study design and sample}

This cross-sectional observational study evaluated patients aged 25 years or older and who had analog or digital panoramic radiography or CBCT examinations requested 
by a dentist independent of this study at Dental Hospital, Universitas Gadjah Mada, Indonesia and were considered eligible for the study. The subjects of this study fulfilled the following inclusion criteria: (1) non-cigarette smoker and/nor alcohol consumer; (2) no exposure to radiographic imaging for the last 3 weeks; (3) no visible lesions in the oral mucosa; (4) not using orthodontic and prosthodontic appliances. Ethical clearance had been granted by the Research Ethics Commission of the Faculty of Dentistry, Universitas Gadjah Mada, Indonesia. The informed consent for each patient was obtained. The sample consisted of ten subjects for each radiological exam selected by purposive sampling design based on the previous study conducted by Shantiningsih and Diba ${ }^{11}$ (2018). The control group included an equal number of subjects who had no radiography examination and were observed under the same research protocol.

Analog panoramic radiographs were obtained using a Yoshida Panoura Deluxe System (The Yoshida Dental MFG. CO., LTD., Tokyo, Japan) with the following exposure parameters: $90 \mathrm{kVp}, 8-10 \mathrm{~mA}$, and $20 \mathrm{~s}$. A digital system using a Pax-i (Vatech, Gyeonggi-do, Republic of Korea) was operated with the following exposure parameters: $72 \mathrm{kVp}, 10 \mathrm{~mA}$, and $16 \mathrm{~s}$. The CBCT images were obtained using a Volux 3D Dental CT System (Genoray, Gyeonggi Province, Republic of Korea) with parameter settings of $85 \mathrm{kVp}, 6 \mathrm{~mA}$, and $16.6 \mathrm{~s}$.

\section{Sample collection and cytopathological analysis}

Smears were collected immediately from buccal mucosa and gingiva cells before X-ray exposure and 10 days later. Before smear collection, the patients were instructed to rinse their mouths with water for $30 \mathrm{~s}$. After rinsing, a cytobrush was used to collect smears over the buccal mucosa and gingiva. Both buccal and gingival mucosa samples were taken twice, before the $\mathrm{X}$-ray exposure on the left region and after the procedure on the right region. The smears were spread onto a glass slide and fixed in 96\% alcohol. The slides were stained by the Papanicolaou method. The stained slides were analyzed under a light microscope (YS100, Nikon, Japan) and Optilab Viewer 2.1.

All slides were analyzed by an experienced and blinded observer. Cells were classified as superficial, intermediate, and parabasal according to the criteria described by Montgomery ${ }^{6}$. The cells were counted until 100 visible, and non-overlapping cells were obtained at 400x magnification on each slide horizontally, from left to right (Figure 1). The results are expressed in percentages. Similar analyzes have been established in previous published studies ${ }^{8,10,12}$.

\section{Statistical data analysis}

All data were presented as mean \pm standard deviation (S.D.). Statistical analysis was performed using IBM ${ }^{\circledR}$ SPSS $®$ Statistics 25 version software (IBM Corporation, Armonk, New York). The normality criterion was evaluated using the Shapiro-Wilk test. Based on the Shapiro-Wilk test results, the normally distributed data were further analyzed using a paired t-test, otherwise using Wilcoxon signed-rank test to examine the difference in the number of superficial, intermediate, and parabasal cells, before and after $\mathrm{X}$-ray exposure. A paired $t$-test was also used to measure 


\section{Parabasal cell $\longrightarrow$}

\section{$\longleftarrow$ Intermediate cell}

\section{Superficial cell}

Figure 1. Papanicolaou staining showing three types of oral mucosa cells. Magnification: 400x.

the differences between buccal mucosa and gingiva of the oral cavity in the study group. The statistical differences were significant if $P<0.05$. The intraclass correlation coefficient (ICC) was used to assess the reproducibility of measurements. Intra-rater reliability statistics for cell numbers were calculated after the same examiner re-evaluated a randomly selected subset of 8 slides after 2 weeks. Based on the 95\% confidence interval of the ICC estimate, the values were interpreted as follows: poor for less than 0.5 , moderate for $0.5-0.75$, good for $0.75-0.9$, and excellent reliability for values greater than $0.9^{13}$.

\section{RESULTS}

Intra-rater reliability measurement was excellent for parabasal cells (ICC $=1$ ) and good for intermediate and superficial cells $(I C C=0.8)$. The cell number was normally distributed by Shapiro-Wilk test, except for parabasal cells. Tables 1 and 2 show the mean frequency differences in percentages of parabasal, intermediate, and superficial cells of buccal mucosa and gingiva, respectively, before and after obtaining analog/digital panoramic or CBCT radiographs and in the control group. A small number of parabasal cells were detected after radiation exposure, but the number was not significant $(p>0.05)$ by Wilcoxon signed-rank test. The paired $t$-test showed a significant increase in intermediate cells $(p<0.05)$, while superficial cells were significantly decreased $(p<0.05)$ after radiation exposure using the three types of radiography methods. No significant differences were observed among all cell types in the control group $(p>0.05)$. 
Table 3 shows the frequency differences between the intermediate and superficial cells in buccal mucosa and gingiva after X-ray exposure under the three types of radiographic methods. No significant differences were observed between the buccal mucosa and gingiva in any radiography methods $(p>0.05)$.

Table 1. Comparison of mean frequencies (in percentages) of parabasal, intermediate, and superficial cells before and after exposure to each radiography imaging in the buccal mucosa.

\begin{tabular}{|c|c|c|c|c|c|c|}
\hline Variable & Parabasal & $p^{\star a}$ & Intermediate & $\mathrm{p}^{\star \mathrm{b}}$ & Superficial & $p^{\star b}$ \\
\hline \multicolumn{7}{|l|}{ Control } \\
\hline Before & 0 & Ref. & $67.80+3.88$ & Ref. & $32.20+3.88$ & Ref. \\
\hline After & 0 & 1 & $69.8+5.31$ & 0.254 & $30.20+5.31$ & 0.254 \\
\hline \multicolumn{7}{|c|}{ Analog Panoramic } \\
\hline Before & 0 & Ref. & $69.50+4.42$ & Ref. & $30.50+4.42$ & Ref. \\
\hline After & $0.083+0.29$ & 0.32 & $75.17+6.89$ & 0.036 & $24.83+6.89$ & 0.036 \\
\hline \multicolumn{7}{|c|}{ Digital Panoramic } \\
\hline Before & 0 & Ref. & $69.70+6.74$ & Ref. & $30.50+8.26$ & Ref. \\
\hline After & $0.33+0.65$ & 0.10 & $81.20+6.37$ & 0.003 & $17.83+7.41$ & 0.000 \\
\hline \multicolumn{7}{|l|}{ СВCT } \\
\hline Before & 0 & Ref. & $67.80+3.88$ & Ref. & $32.89+3.41$ & Ref. \\
\hline After & $0.5+0.71$ & 0.059 & $77.6+9.80$ & 0.013 & $22.67+9.51$ & 0.018 \\
\hline
\end{tabular}

Table 2. Comparison of mean frequencies (in percentages) of parabasal, intermediate, and superficial cells before and after exposure to each radiography imaging in the gingiva.

\begin{tabular}{|c|c|c|c|c|c|c|}
\hline Variable & Parabasal & $p^{\star a}$ & Intermediate & $\mathrm{p}^{\star \mathrm{b}}$ & Superficial & $p^{* b}$ \\
\hline \multicolumn{7}{|l|}{ Control } \\
\hline Before & 0 & Ref. & $58.10+7.49$ & Ref. & $41.9+7.49$ & Ref. \\
\hline After & 0 & 1 & $63.00+9.59$ & 0.186 & $37.00+9.59$ & 0.186 \\
\hline \multicolumn{7}{|c|}{ Analog Panoramic } \\
\hline Before & 0 & Ref. & $61.08+6.71$ & Ref. & $38.92+6.71$ & Ref. \\
\hline After & $0.083+0.29$ & 0.32 & $67.75+5.24$ & 0.039 & $31.42+5.55$ & 0.017 \\
\hline \multicolumn{7}{|c|}{ Digital Panoramic } \\
\hline Before & 0 & Ref. & $60.60+8.06$ & Ref. & $41.83+9.28$ & Ref. \\
\hline After & $0.33+0.65$ & 0.10 & $79.40+6.42$ & 0.000 & $20.83+7.48$ & 0.000 \\
\hline \multicolumn{7}{|l|}{ СВСТ } \\
\hline Before & 0 & Ref. & $58.1+7.49$ & Ref. & $43.33+6.32$ & Ref. \\
\hline After & $0.5+0.71$ & 0.059 & $73.70+7.36$ & 0.001 & $26.11+9.02$ & 0.001 \\
\hline
\end{tabular}

a Wilcoxon signed-rank test

b Paired t-test

*Comparison of the reference group (Ref.); differences were considered to be statistically significant when $p<0.05$. 
Table 3. Comparison of frequency differences of intermediate and superficial cells in buccal mucosa and gingiva before and after exposure to each radiography imaging between buccal mucosa and gingiva

\begin{tabular}{lccc}
\hline Cell types & Buccal & Gingival & p-value*a \\
\hline Analog Panoramic & & & \\
\hline Intermediate & 5.67 & 6.67 & 0.773 \\
\hline Superficial & -5.67 & -7.50 & 0.577 \\
\hline Digital Panoramic & & & \\
\hline Intermediate & 11.50 & 18.80 & 0.069 \\
\hline Superficial & -12.75 & -21.00 & 0.085 \\
\hline CBCT & & & \\
\hline Intermediate & 9.80 & 15.60 & 0.252 \\
\hline Superficial & -11.30 & -14.10 & 0.584 \\
\hline
\end{tabular}

a Paired $t$-test

*Differences were considered to be statistically significant when $p<0.05$.

\section{DISCUSSION}

The cytotoxic effects of panoramic and CBCT lead to cell death $h^{3,4,14,15}$. Cellular death is believed to be a nongenotoxic mechanism induced by carcinogenesis ${ }^{1,2}$. Genotoxic and cytotoxic $X$-ray effects on exfoliated buccal mucosal and gingival cells were detected when a series of $\mathrm{X}$-ray dental imaging exams, including full mouth radiograph, panoramic, lateral cephalometric radiographs, posteroanterior cephalometric radiographs, and CBCTs, were performed ${ }^{14-16}$. Further, analog panoramic radiographs showed a significant increase in post-exposure micronuclei relative to digital panoramic radiographs ${ }^{12}$. Exposure to carcinogens also affects the maturation pattern of the oral mucosa, as detected by Papanicolaou ${ }^{10}$. This study aimed to evaluate whether $X$-ray radiation from dental imaging affects buccal mucosa and gingiva epithelium maturation patterns. This research is the first study to assess the maturation patterns after dental imaging by cytopathology.

Oral epithelium maturation involves several widely studied confounding factors, such as mouth rinse utilization, oral lesion, the use of orthodontic and prosthodontic appliances, smoking, and alcohol usage $e^{8,10,17-19}$. In this study, the patient with those confounding factors was excluded. The first cell count represented any consequences of cytotoxic agents before radiation exposure. Therefore, any differences emerging between before and after radiation exposure can be attributed to radiation.

This study showed that normal mucosa smears contained no parabasal cell, and no significant change was noted in the intermediate and superficial cell numbers for 10 days. Burzlaff et al. have confirmed that cells in the superficial and intermediate layers and, in rare cases, the parabasal layer are normally observed in oral mucosal smears ${ }^{8}$. Normal maturation pattern shows the balanced proportions of cells categorized as superficial, intermediate, and parabasal in exfoliated cells. The alteration in oral epithelial cell composition is related to the abnormal composition of cell 
types. Cytopathological studies to assess the maturation pattern of oral mucosal cells of patients exposed to tobacco and alcohol found fewer superficial cells and an increased number of intermediate cells ${ }^{8}$. These findings are in line with our results that more intermediate cells were detected after radiation exposure, implying the alteration of maturation pattern.

In the present study, the number of intermediate cells increased $(p<0.05)$, whereas that of superficial cells decreased $(p<0.05)$ after exposure to analog/digital panoramic or CBCT. This finding may correlate with the cytotoxicity effect of dental imaging on oral mucosa cells. X-ray exposure during panoramic dental radiography triggers a cytotoxic effect by increasing apoptosis ${ }^{1}$. The number of karyolytic, karyorrhexic, and pyknotic cells showed a significant increase after panoramic radiography and CBCT scan ${ }^{3,14}$. These types of cells represent the cell death process, which enables the elimination of defected cells, resulting in a massive discharge of superficial cells followed by increased mitosis on the parabasal layer as replacement ${ }^{20}$. The homeostatic mechanism of the parabasal layer that produces new cells replaces the loose cells; the more severe the lesion, the more parabasal cells are found ${ }^{8,21}$. Moreover, parabasal cells were detected after $X$-ray radiation, although the statistic calculation was not significant $(p>0.05)$ compared with that before radiation. We consider that the cytobrush swab may not reach the deepest layers of the oral mucosal epithelium. Cytohistological techniques showed a limited sensitivity of between 79 and $97 \%$.

Buccal mucosa and gingiva showed no difference in the number of cells before and after analog/digital panoramic radiography and CBCT $(p>0.05)$. Yang et al. verified that the number of nuclear changes in both sites, including those in karyorrhexis, condensed chromatin, pyknosis, and karyolysis, showed no significant increase before and after CBCT scan ${ }^{14}$. However, Kesidi et al. compared the differences in micronuclei and other nuclear alterations in buccal mucosa and gingiva after exposure by conventional full mouth radiograph procedure, which revealed a substantial difference with the mean difference being high in the buccal mucosa compared to the gingiva ${ }^{14}$. This condition may be explained by the differences in radiography, indicating variations in the dosage. Differences in radiation dose and repeated exposure may increase the radiation effect on the body, as studies have proven that cellular death increases with radiation dose $^{23}$.

There may be some possible limitations in this study. The first limitation is the reliability of cell frequency measurement within an observer. To avoid this limitation, we assessed intra-rater reliability that reflects the variation of data measurement performed by the observer. Intra-rater measurement showed good to excellent reliability in this study. The second limitation concerns the absence of anucleated superficial cell measurement; hence the keratinization index cannot be determined. The keratinization index may be established in future research to provide additional information as a marker to detect early cell changes in oral cancer.

The results from the present study suggest that routine $X$-ray dental imaging exams, such as analog/digital panoramic and CBCT, can induce changes in the maturation pattern of buccal mucosa and gingiva epithelium. 


\section{ACKNOWLEDGEMENT}

The authors would like to thank the Faculty of Dentistry, Universitas Gadjah Mada for Ryna Dwi Yanuaryska (grant number 4305/UN1/FKG1/Set.KG1/PT/2019) for providing the financial support to execute this study.

\section{References}

1. Cerqueira EMM, Gomes-Filho IS, Trindade S, Lopes MA, Passos JS, Machado-Santelli GM. Genetic damage in exfoliated cells from oral mucosa of individuals exposed to X-rays during panoramic dental radiographies. Mutat Res. 2004;562(11):111-7. doi: 10.1016/j.mrgentox.2004.05.008

2. Angelieri F, de Oliveira GR, Sannomiya EK, Ribeiro DA. DNA damage and cellular death in oral mucosa cells of children who have undergone panoramic dental radiography. Pediatr Radiol. 2007;37(6):561-5. doi: 10.1007/s00247-007-0478-1.

3. Suomalainen A, Esmaeili E P, Robinson S. Dentomaxillofacial imaging with panoramic views and cone beam CT. Insights into Imaging. 2015;6(1):1-16. doi: 10.1007/s13244-014-0379-4.

4. Lorenzoni DC, Fracalossi ACC, Carlin V, Ribeiro DA, Sant'anna EF. Mutagenicity and cytotoxicity in patients submitted to ionizing radiation. Angle Orthod. 2013 Jan;83(1):104-9. doi: 10.2319/013112-88.1.

5. Mally A, Chipman JK. Non-genotoxic carcinogens: early effects on gap junctions, cell proliferation and apoptosis in the rat. Toxicology. 2002 Dec;180(3):233-48. doi: 10.1016/s0300-483x(02)00393-1.

6. Montgomery PW. A study of exfoliative cytology of normal human oral mucosa. J Dent Res. 1951 Feb;30(1):12-8. doi: 10.1177/00220345510300010501.

7. Holland N, Bolognesi C, Kirsch-Volders M, Bonassi S, Zeiger E, Knasmueller S, et al. The micronucleus assay in human buccal cells as a tool for biomonitoring DNA damage: the HUMN project perspective on current status and knowledge gaps. Mutat Res. 2008;659(1-2):93-108 doi: 10.1016/j.mrrev.2008.03.007.

8. Burzlaff JB, Bohrer PL, Paiva RL, Visioli F, Sant'Ana Filho M, da Silva VD, et al. Exposure to alcohol or tobacco affects the pattern of maturation in oral mucosal cells: a cytohistological study. Cytopathology. 2007 Dec;18(6):367-75. doi: 10.1111/j.1365-2303.2007.00473.x.

9. Abdelaziz MS, Osman TE. Detection of cytomorphological changes in oral mucosa among alcoholics and cigarette smokers. Oman Med J. 2011 Sep;26(5):349-52. doi: 10.5001/omj.2011.85.

10. Baumgart CdS, Daroit NB, Maraschin BJ, Haas AN, Visioli F, Rados PV. Influence of factors in the oral mucosa maturation pattern: a cross-sectional study applying multivariate analyses. Braz J Oral Sci 2016;15:27-34. doi: 10.20396/bjos.v15i1.8647094.

11. Shantiningsih RR, Diba SF. Biological changes after dental panoramic exposure: conventional versus digital. Dent J (Majalah Kedokteran Gigi) 2018;51(1):25-8. doi: 10.20473/j.djmkg.v51.i1.p25-28.

12. Sandhu M, Mohan V, Kumar JS. Evaluation of genotoxic effect of X-rays on oral mucosa during panoramic radiography. J Indian Acad Oral Med Radiol. 2015;27(1):25-8. doi: 10.4103/0972-1363.167070

13. Koo TK, Li MY. A guideline of selecting and reporting intraclass correlation coefficients for reliability research. J Chiropr Med. 2016 Jun;15(2):155-63. doi: 10.1016/j.jcm.2016.02.012.

14. Kesidi S, Maloth KN, Reddy KK, Geetha P. Genotoxic and cytotoxic biomonitoring in patients exposed to full mouth radiographs - A radiological and cytological study. J Oral Maxillofac Radiol. 2017;5(1):1-6. doi: 10.4103/jomr.jomr_47_16. 
15. Yang P, Hao S, Gong X, Li G. Cytogenetic biomonitoring in individuals exposed to cone beam CT: comparison among exfoliated buccal mucosa cells, cells of tongue and epithelial gingival cells. Dentomaxillofac Radiol. 2017;46(5):20160413. doi: 10.1259/dmfr.20160413.

16. Li G, Yang P, Hao S, Hu W, Liang C, Zou BS, et al. Buccal mucosa cell damage in individuals following dental X-ray examinations. Sci Rep. 2018:6:8(1):2509. doi: 10.1038/s41598-018-20964-3.

17. Ribeiro DA, Angelieri F. Cytogenetic biomonitoring of oral mucosa cells from adults exposed to dental X-rays. Radiat Med. 2008;26(6):325-30. doi: 10.1007/s11604-008-0232-0.

18. Tandelilin RTC, Jonarta AL, Widita E. Maturation index assessment of sodium tripolyphosphate and tetra potassium pyrophosphate based calculus dissolution mouthrinse (periogen $®$ ) in moderate gingivitis patients: a histopathological study. JDHODT 2017;6:166-70. doi: 10.15406/jdhodt.2017.06.00218.

19. Arruda EP, Trevilatto PC, Camargo ES, Woyceichoski IE, Machado MA, Vieira I, et al. Preclinical alterations of oral epithelial cells in contact with orthodontic appliances. Biomed Pap Med Fac Univ Palacky Olomouc Czech Repub. 2011;155(3):299-303. doi: 10.5507/bp.2011.043.

20. Squier CA, Kremer MJ. Biology of oral mucosa and esophagus. J Natl Cancer Inst Monogr. 2001;(29):7-15. doi: 10.1093/oxfordjournals.jncimonographs.a003443.

21. Thomas P, Holland N, Bolognesi C, Kirsch-Volders M, Bonassi S, Zeiger E, et al. Buccal micronucleus cytome assay. Nat Protoc. 2009;4(6):825-37. doi: 10.1038/nprot.2009.53.

22. Jagannathan N, Ramani P, Premkumar P, Natesan A, Sherlin HJ. Epithelial maturation pattern of dysplastic epithelium and normal oral epithelium exposed to tobacco and alcohol: a scanning electron microscopic study. Ultrastruct Pathol. 2013;37(3):171-5. doi: 10.3109/01913123.2013.766292.

23. He JL, Chen WL, Jin LF, Jin HY. Comparative evaluation of the in vitro micronucleus test and the comet assay for the detection of genotoxic effects of X-ray radiation. Mutat Res. 2000;469(2):223-31. doi: 10.1016/S1383-5718(00)00077-2. 